\title{
Cadmium in blood and urine related to present and past exposure. A study of workers in an alkaline battery factory
}

\author{
EJDA HASSLER, B LIND, AND M PISCATOR \\ From the Department of Environmental Hygiene, Karolinska Institute, and the National Institute of \\ Environmental Medicine, Stockholm, Sweden
}

ABSTRACT Blood and urinary cadmium concentrations together with cadmium in air concentrations from the breathing zone of 18 male workers in an alkaline battery factory were determined at regular intervals for 11 consecutive weeks. Nine of the workers examined were smokers and nine non-smokers. Smokers and non-smokers did not differ in age or years of employment. Cadmium in air concentrations varied, but no definite trend was observed. The concentrations of cadmium in the blood and urine were found to be stable. Exposure to airborne cadmium was identical for smokers and non-smokers but average cadmium concentrations in the blood and urine of smokers were approximately twice as high as those in non-smokers. For the whole group, urinary cadmium was significantly correlated with years of employment, but no correlation was found between blood cadmium concentrations and exposure. For non-smokers, the correlation between cadmium in blood and years of employment was statistically significant $(p<0 \cdot 001)$. This finding indicated that blood concentrations of cadmium reflect body burden in non-smokers at current low exposure levels.

Occupational exposure standards for cadmium are set to protect workers from its toxic effects, particularly effects on the kidney. In Sweden the threshold limit value for total cadmium dust is $50 \mu \mathrm{g} \mathrm{Cd} / \mathrm{m}^{3}$ air; the concentration of respirable cadmium dust is limited to $20 \mu \mathrm{g} \mathrm{Cd} / \mathrm{m}^{3}$ air. In addition to controlling the cadmium concentration in workroom air, regular medical examinations are prescribed for cadmium workers.

Cadmium in blood is assumed to reflect recent exposure. According to Swedish regulations issued in $1978^{1}$ a thorough medical examination of the worker should be performed when blood cadmium concentrations exceed $22.4 \mu \mathrm{g} / 1(=200 \mathrm{nmol} / \mathrm{l})$. At levels exceeding $33.6 \mu \mathrm{g} / \mathrm{l}(=300 \mathrm{nmol} / \mathrm{l})$, the worker is removed from exposure until the blood cadmium concentration falls below $11.2 \mu \mathrm{g} / \mathrm{l}(=100$ nmol/l).

Since cadmium has an extremely long biological half life, it is reasonable to assume that blood and urinary concentrations, at least to a certain extent, reflect the body burden of cadmium and thus are

Received: 13 September 1982

Accepted: 22 November 1982 influenced by exposure that took place decades earlier.

A study by Adamsson showed that the average cadmium concentration in workroom air in a Swedish alkaline battery factory had decreased from about $5000 \mu \mathrm{g} \mathrm{Cd} / \mathrm{m}^{3}$ air in 1946 to about $10 \mu \mathrm{g}$ $\mathrm{Cd} / \mathrm{m}^{3}$ air in $1976 .^{2}$

The aims of the present study were twofold:

(1) To determine the magnitude of variation over time of cadmium in the blood and urine of workers in a factory where continuous exposure to cadmium dust had occurred.

(2) To investigate to what degree exposure to current low atmospheric concentrations of cadmium affect the balance of cadmium concentrations in the blood and urine of workers who have already been exposed for several years.

\section{Material and methods}

Eighteen male volunteers participated in the study. Cases 1-15 are the same subjects as described by Adamsson et al. ${ }^{3} \mathrm{At}$ the time of the investigation the subjects did not wear protective masks. Table 1 gives personal data for each case. 
Table 1 Personal data of subjects studied

\begin{tabular}{lllr}
\hline Case & Age (years) & Smoking habits & Years of employment \\
\hline 1 & 28 & Smoker & 2 \\
2 & 30 & Smoker & 2 \\
3 & 43 & Smoker & 3 \\
4 & 57 & Smoker & 3 \\
5 & 58 & Smoker & 5 \\
6 & 48 & Smoker & 9 \\
7 & 58 & Smoker & 20 \\
8 & 31 & Non-smoker & 4 \\
9 & 42 & Non-smoker & 4 \\
10 & 53 & Non-smoker & 4 \\
11 & 56 & Non-smoker & 4 \\
12 & 34 & Non-smoker & 7 \\
13 & 60 & Non-smoker & 12 \\
14 & 46 & Non-smoker & 13 \\
15 & 58 & Non-smoker & 26 \\
16 & 53 & Smoker & 17 \\
17 & 58 & Smoker & 20 \\
18 & 56 & Non-smoker & 29 \\
& & & \\
Average & 48 & & 10 \\
\hline
\end{tabular}

The study was performed during the first quarter of 1977. Samples of cadmium in air, blood, and urine were collected over a period of 11 weeks.

Case 15 was transferred to a non-exposed area during the second week of the study since his beta-2-microglobulin excretion was found to be above the acceptable limit. ${ }^{1}$

To measure the cadmium concentrations in ambient air, each worker wore a personal sampler equipped with a cyclone for one shift a week. Sampling time was about three hours. The detection limit was $0.4 \mu \mathrm{g} \mathrm{Cd} / \mathrm{m}^{3}$ air. For details on sampling and treatment of filters see Adamsson. ${ }^{2}$

One blood sample was taken from each subject on alternate Fridays. Samples were stored at $-20^{\circ} \mathrm{C}$ and analysed once for each subject with a modified Delves's cup technique. A set of five cups each containing $10 \mu \mathrm{l}$ of the sample was used for every sample according to the method described by Ulander and Axelson. ${ }^{4}$ Standards were prepared by spiking blood with a low cadmium content with cadmium metal. The mean sensitivity of the method was 0.096 absorbance seconds for a blood sample containing $10 \mu \mathrm{g} \mathrm{Cd} / \mathrm{l}$. The average detection limit was $0.3 \mu \mathrm{g}$ $\mathrm{Cd} / \mathrm{l}$ blood. To check the precision of the method, three internal standards were prepared from samples analysed previously. Pools of blood containing $<2 \mathrm{ng} \mathrm{Cd} / \mathrm{g}, 2-5 \mathrm{ng} \mathrm{Cd} / \mathrm{g}$, and 5-10 ng Cd/g were collected. These internal standards were divided into a large number of small aliquots and stored frozen. Subsequently one internal standard of each concentration was run together with the samples. Fifteen analyses for each concentration gave arithmetic means \pm one standard deviation of $1 \cdot 5 \pm 0.8$, $4 \cdot 3 \pm 0 \cdot 7$, and $8 \cdot 6 \pm 1 \cdot 3 \mathrm{ng} \mathrm{Cd} / \mathrm{g}$ blood, respectively. To check the accuracy of the method, internal standards were also analysed by neutron activation analysis. The results were $1 \cdot 2,4 \cdot 7$, and $8 \cdot 8 \mathrm{ng} \mathrm{Cd} / \mathrm{g}$ blood, respectively.

Samples of urine were collected before work every Monday morning during the entire period of investigation and stored at $-20^{\circ} \mathrm{C}$. Cadmium analyses were performed using a method described by Elinder et al. ${ }^{5}$ Mean sensitivity was 0.126 absorbance seconds for a solution of methylisobutylketone (MIBK) containing $4 \mathrm{ng} \mathrm{Cd} / \mathrm{ml}$ which will give $3.5 \mathrm{ng} \mathrm{Cd} / \mathrm{ml}$ MIBK for $1 \%$ absorbance seconds. The detection limit was, on average, $1.25 \mathrm{ng}$ $\mathrm{Cd} / \mathrm{ml} \mathrm{MIBK}$, which corresponded to $0.05 \mu \mathrm{g} \mathrm{Cd} / \mathrm{l}$ urine. Precision, expressed as the mean coefficient of variation, was $6 \%$ for duplicates. Creatinine was determined according to Hare. ${ }^{6}$

The individual biological data were found to fit the requirements of normality, ${ }^{7}$ but the atmospheric data were log-normally distributed. The cadmium in air results were therefore log-transformed for statistical treatment and the confidence limits were computed according to Coenen. ${ }^{8}$ Since the relationship between different parameters may be curved and a single point at the extreme range may give gross distortion, both linear and rank correlation coefficients were considered.

\section{Results}

Case 15, who had been employed for 26 years and had previously worked under far worse conditions, ${ }^{2}$ displayed gradually decreasing concentrations of cadmium in his blood and urine. These changes were not significant. Because of the possible influence of a changing metabolic pattern due to subclinical renal dysfunction, case 15 was excluded from the comparison of different parameters.

The arithmetic mean of cadmium in the workroom atmosphere based on 181 observations was $7.6 \mu \mathrm{g} \mathrm{Cd} / \mathrm{m}^{3}$ air with $95 \%$ confidence limits of $7 \cdot 1$ $\mu \mathrm{g} \mathrm{Cd} / \mathrm{m}^{3}$ air and $8.8 \mu \mathrm{g} \mathrm{Cd} / \mathrm{m}^{3}$ air.

The arithmetic mean of cadmium in blood for the whole group was $14 \cdot 1 \mu \mathrm{g} \mathrm{Cd} / \mathrm{l}$ blood and the average level of cadmium in urine was $6.8 \mu \mathrm{g} \mathrm{Cd} / \mathrm{l}$ urine or $4.9 \mu \mathrm{g} \mathrm{Cd} / \mathrm{g}$ creatinine. Table 2 shows individual cadmium concentrations in air, blood, and urine. Individual variations of cadmium concentration in blood and urine are described by applying the coefficients of variation.

The average cadmium concentrations in blood and urine samples from smokers and non-smokers were significantly different. The cadmium concentrations in the blood and urine of smokers were approximately twice those for non-smokers. Table III gives arithmetic and geometric means for different parameters for smokers and non-smokers, respectively. 
Table 2 Cadmium concentrations in air, blood, and urine. Arithmetic means $(A M)$ and coefficients of variation $\left(C^{*}\right)$

\begin{tabular}{|c|c|c|c|c|c|c|c|c|}
\hline \multirow[b]{2}{*}{ Case } & \multicolumn{2}{|c|}{$\begin{array}{l}\text { Cd in air } \\
\left(\mu g / m^{3}\right)\end{array}$} & \multicolumn{2}{|c|}{$\underset{(\mu g / l)}{C d \text { in } \text { blood }^{b}}$} & \multicolumn{2}{|c|}{$\begin{array}{l}\text { Cd in urinec } \\
(\mu g / g \text { creat })\end{array}$} & \multicolumn{2}{|l|}{$(\mu g / l)$} \\
\hline & $A M^{d}$ & & $A M$ & $C^{*}$ & $A M$ & $C^{*}$ & $A M$ & $C^{*}$ \\
\hline $\begin{array}{r}1 \\
2 \\
3 \\
4 \\
5 \\
6 \\
7 \\
8 \\
9 \\
10 \\
11 \\
12 \\
13 \\
14 \\
15 \\
16 \\
17 \\
18\end{array}$ & $\begin{array}{c}7 \cdot 8 \\
10 \cdot 3 \\
8 \cdot 1 \\
6 \cdot 9 \\
10 \cdot 2 \\
5 \cdot 8 \\
6 \cdot 6 \mathrm{~g} \\
7 \cdot 3 \\
9 \cdot 0 \\
7 \cdot 4^{\mathrm{f}} \\
6 \cdot 5 \mathrm{~g} \\
4 \cdot 8 \\
7 \cdot 2 \\
9 \cdot 0 \\
-6 \cdot 3 \\
8 \cdot 5 \mathrm{f} \\
6 \cdot 7\end{array}$ & 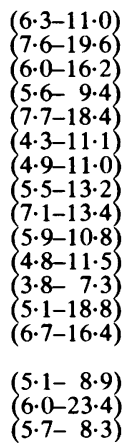 & $\begin{array}{c}12 \cdot 7 \\
8 \cdot 5 \\
18 \cdot 1 \\
59 \cdot 9 \\
16 \cdot 2 \\
14 \cdot 2 \\
25 \cdot 9 \\
5 \cdot 6 \\
6 \cdot 7 \\
7 \cdot 1 \mathrm{~h} \\
5 \cdot 0 \\
6 \cdot 1 \\
12 \cdot 7 \\
8 \cdot 4 \\
11 \cdot 8 \\
12 \cdot 0 \\
6 \cdot 7 \\
13 \cdot 4\end{array}$ & $\begin{array}{r}27 \\
3 \\
13 \\
3 \\
3 \\
12 \\
32 \\
12 \\
24 \\
35 \\
18 \\
15 \\
20 \\
34 \\
11 \\
20 \\
15 \\
16\end{array}$ & $\begin{array}{c}1 \cdot 8^{\mathrm{e}} \\
0 \cdot 8 \\
1 \cdot 6 \\
21 \cdot 1 \\
1 \cdot 9^{\mathrm{e}} \\
6 \cdot 9 \\
8 \cdot 5 \\
1 \cdot 4^{\mathrm{e}} \\
2 \cdot 3 \\
1 \cdot 8 \\
0 \cdot 4 \mathrm{~g} \\
1 \cdot 4 \\
7 \cdot 1 \\
3 \cdot 0 \\
9 \cdot 2 \\
10 \cdot 8 \\
4 \cdot 6 \\
7.7\end{array}$ & $\begin{array}{l}59 \\
24 \\
15 \\
23 \\
33 \\
28 \\
18 \\
13 \\
48 \\
30 \\
28 \\
25 \\
15 \\
58 \\
22 \\
27 \\
21 \\
16\end{array}$ & $\begin{array}{c}2 \cdot 0^{\mathrm{e}} \\
1 \cdot 2 \\
1 \cdot 9 \\
32 \cdot 4 \\
3 \cdot 5^{\mathrm{e}} \\
11 \cdot 1 \\
12 \cdot 6 \\
2 \cdot 7^{\mathrm{e}} \\
5 \cdot 5 \\
3 \cdot 1 \\
0 \cdot 8 \mathrm{~g} \\
2 \cdot 9 \\
12 \cdot 3 \\
3 \cdot 7 \\
15 \cdot 2 \\
6 \cdot 2 \\
5 \cdot 9 \\
8 \cdot 2\end{array}$ & $\begin{array}{l}57 \\
47 \\
24 \\
17 \\
35 \\
44 \\
24 \\
31 \\
32 \\
41 \\
27 \\
29 \\
19 \\
58 \\
21 \\
58 \\
34 \\
18\end{array}$ \\
\hline Average & $7 \cdot 6$ & $(7 \cdot 1-8 \cdot 8)$ & $14 \cdot 1$ & 17 & $6 \cdot 8$ & 28 & $4 \cdot 9$ & 35 \\
\hline
\end{tabular}

aEleven observations if not otherwise stated.

bFive observations if not otherwise stated.

cTwelve observations if not otherwise stated.

d Confidence limits based on log-normal distribution within hrackets; $95 \%$.

'Eleven observations.

f Ten observations.

gNine observations.

hFour observations.

Table 3 Personal data and cadmium concentrations in smokers and non-smokers. Arithmetic means with geometric means within parentheses for different parameters

\begin{tabular}{|c|c|c|c|c|}
\hline Parameter & Smok & cers & Non & smokers \\
\hline $\begin{array}{l}\text { No of cases } \\
\text { Age (years) } \\
\text { Years of e mployment } \\
\text { Cd in air, } \mu \mathrm{g} / \mathrm{m}^{3} \\
\text { Cd in blood, } \mu \mathrm{g} / 1 \\
\text { Cd in urine, } \mu \mathrm{g} / \mathrm{g} \text { creatinine } \\
\text { Cd in urine, } \mu \mathrm{g} / \mathrm{l}\end{array}$ & $\begin{array}{r}48 \\
9 \\
7.8 \\
19.4 \\
6.5 \\
8.5\end{array}$ & $\begin{array}{l}9 \\
(47) \\
(6) \\
\left(\begin{array}{c}7 \cdot 7 \\
15 \cdot 6 \\
4 \cdot 0\end{array}\right) \\
(5 \cdot 2)\end{array}$ & $\begin{array}{r}47 \\
10 \\
7 \cdot 2 \\
8 \cdot 1 \\
3 \cdot 1 \\
4 \cdot 9\end{array}$ & $\begin{array}{l}8 \\
(46) \\
(7) \\
\left(\begin{array}{l}7 \cdot 1) \\
7 \cdot 6 \\
2 \cdot 2 \\
3 \cdot 8\end{array}\right)\end{array}$ \\
\hline
\end{tabular}

No definite trend of cadmium concentrations in the workroom atmosphere was observed and comparisons between weekly geometric means of cadmium in air for smokers and non-smokers showed no significant differences. Nor could any definite trend be shown for blood concentrations or for urinary concentrations of cadmium and there was no covariance between concentrations of cadmium in blood and cadmium in urine over time (fig 1). Geometric means were chosen in the graphic description because of the skewed distributions of the data.

Cadmium in blood and urine correlated well (fig 2 ). The linear correlation coefficient was +0.84 ( $p<$ $0 \cdot 001)$ and Spearman's rank correlation coefficient was $+0.60(\mathrm{p}<0.01)$. When the value for case 4 was excluded, however, the correlation coefficients

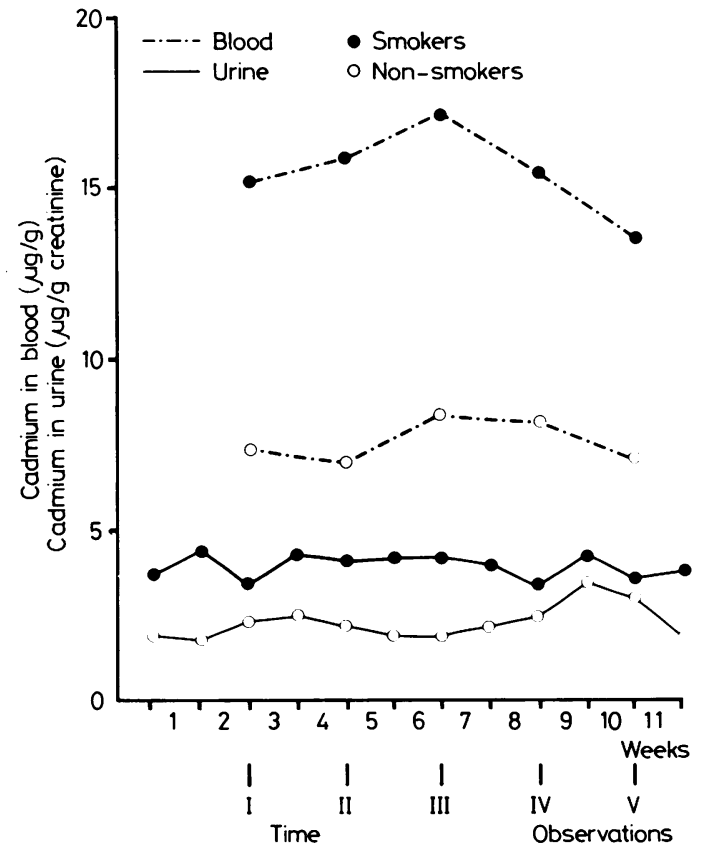

Fig 1 Variation of cadmium in blood $(B-C d, \mu / l)$ and urine (U-Cd, $\mu / g$ creatinine) with time. Geometric means of samples from smokers and non-smokers. 


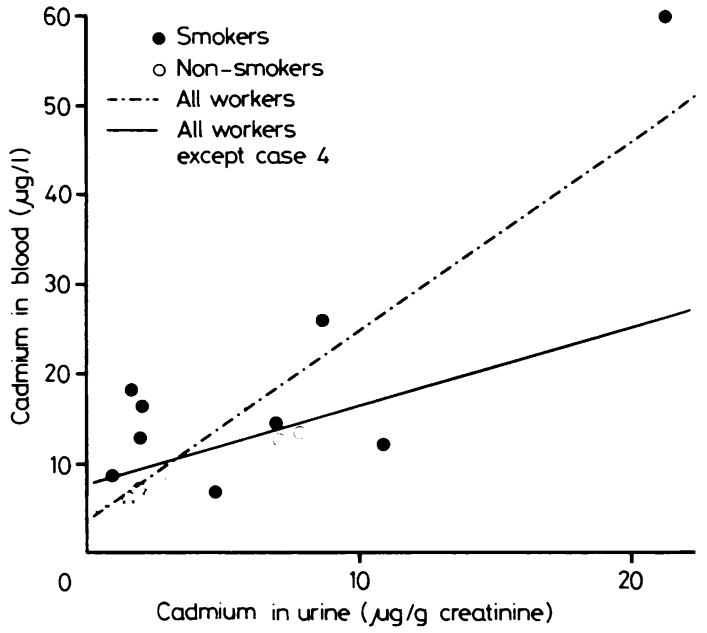

Fig 2 Arithmetic means of cadmium in blood (B-Cd, $\mu \mathrm{g} / \mathrm{l})$ $v$ arithmetic means of cadmium in urine $(U-C d, \mu g / g$ creatinine).

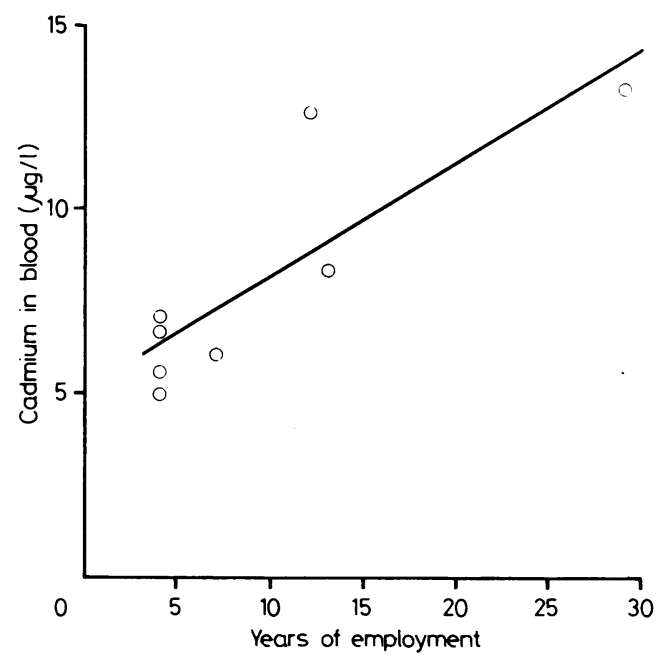

Fig 3 Arithmetic means of cadmium in blood (B-Cd, $\mu \mathrm{g} / \mathrm{l})$ $v$ years of employment for non-smokers.

decreased to $r_{\text {lin }}=+0.50(p<0.05)$ and $r_{s}=+0.52$ $(p<0.05)$. For non-smokers only, the correlation between cadmium in blood and cadmium in urine was excellent: $r_{\text {lin }}=+0.99$ and $r_{s}=+0.97(p<$ ().001).

Cadmium in blood did not correlate with years of employment for the whole group. For non-smokers, however, the correlation between cadmium in blood and years of employment was statistically significant (fig 3). The linear correlation coefficient was +0.85

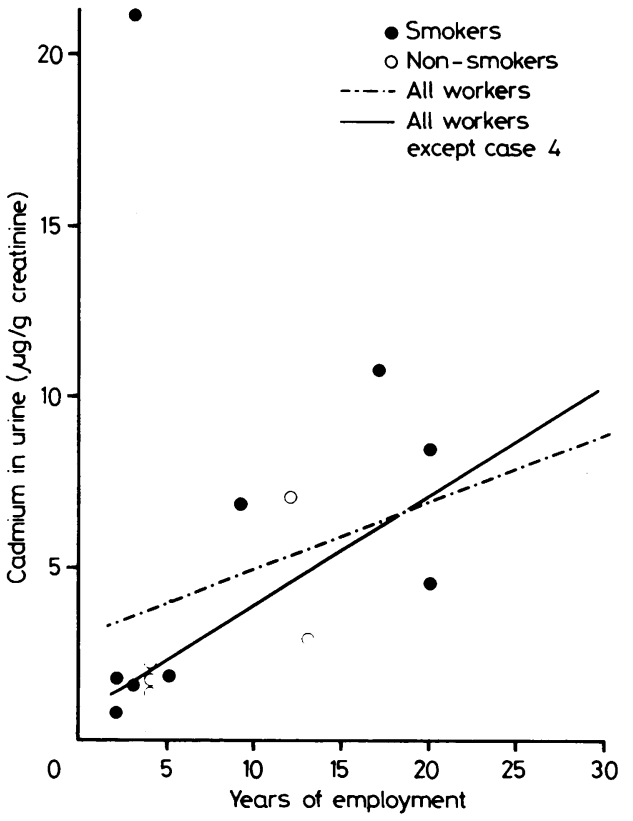

Fig 4 Arithmetic means of cadmium in urine $(U-C d, \mu g / g$ creatinine) $v$ years of employment.

$(\mathrm{p}<0.001)$ and the rank correlation coefficient was $+0.80(p<0.05)$. The equation of the regression line was: cadmium in blood $(\mu \mathrm{g} / \mathrm{l})=5 \cdot 1+0.31 \times$ years of employment.

The rank correlation coefficient between cadmium in urine and years of employment was +0.58 $(p<0.05)$ for the whole group. The linear correlation coefficient was non-significant $(=+0 \cdot 30)$. When case 4 was excluded, the linear correlation increased to $+0.78(p<0.001)$ and the equation of the regression line became: cadmium in urine $(\mu \mathrm{g} / \mathrm{g}$ creatinine $)=0.83+0.32 \times$ years of employment (fig 4).

\section{Discussion}

In the present study case 4 had cadmium concentrations in blood and urine two or three times as high as those of the other workers due to inadequate personal hygiene.$^{39}$ The high cadmium concentrations in the blood and urine of case 15 as well as the insignificant decrease after cessation of exposure may be explained by the high body burden of cadmium and its long biological half life.

The concentrations of cadmium in blood and urine were found to be stable during the entire period of investigation. Therefore, it can be assumed that once certain concentrations of cadmium in blood and urine have been reached, additional 
exposure to low concentrations of airborne cadmium does not influence the cadmium concentrations in human fluids over a short time. This observation is in agreement with that of Kjellström, ${ }^{10}$ who studied newly employed workers in the same factory as that investigated in the present study.

Atmospheric cadmium concentrations were generally low and were of the same order as those for some of the controls used in the study by Lauwerys et al. "As in the present study, these authors found a significant correlation between the cadmium concentrations in blood and urine. They did not observe, however, any correlation between blood cadmium and years of employment. This was also the case for the whole group in the present study. The correlation was significant in non-smokers only.

Cadmium in blood is supposed mainly to reflect recent exposure.$^{10}$ In the eight compartment model of cadmium metabolism proposed by Nordberg and Kjellström, ${ }^{12}$ however, it was stated that a fraction of cadmium in blood was related to body burden. It thus seems reasonable to assume that, particularly for workers who had previously been heavily exposed to cadmium, this fraction may be larger than the blood cadmium content due to actual exposure at current low exposure levels.

By contrast with the conclusions drawn by Lauwerys et $\mathrm{l}^{11}$, the present measurements showed a correlation between cadmium in urine and years of employment. The intercept of the regression line $(0.83 \mu \mathrm{g} \mathrm{Cd} / \mathrm{g}$ creatinine $)$ fits well with the urinary excretion of cadmium found among nonoccupationally exposed men in Sweden. ${ }^{513}$ It should be pointed out that even if the number of cases studied was small the repeated analyses of cadmium in blood and urine ensure very reliable estimates.

The higher cadmium concentrations in the blood and urine of smokers indicate a higher degree of cadmium exposure, probably caused by contamination of cigarettes or pipes. Smokers often carried cigarettes or pipes in their overall pockets and started to smoke before they had left the assembly hall. Contamination of cigarettes and pipe tobacco by a thin layer of cadmium oxide was reported by Piscator et $\mathrm{l}^{14}$; this adds to the contamination in the tobacco itself. It is also possible that cadmium dust becomes fume-like during smoking. Absorption of cadmium fume in the lung is considered to be higher than the absorption of particles. ${ }^{13}$

Urinary excretion of cadmium in different individuals varied more with time than did the concentration of cadmium in blood (see table 2). This is not surprising since urine is a more variable medium than blood. Urine can be more or less diluted and dilution increases the analytical error. If diluted urines (specific gravity $\leqslant 1.010$ ) were excluded the arithmetic means of urinary cadmium generally decreased and the coefficients of variation became lower. For example, the arithmetic mean of 12 observations was $3.0 \mu \mathrm{g} \mathrm{Cd} / \mathrm{g}$ creatinine and the coefficient of variation was $58 \%$. When diluted samples were excluded, the arithmetic mean of the remaining 10 samples was $2.3 \mu \mathrm{g} \mathrm{Cd} / \mathrm{g}$ creatinine and the coefficient of variation was $24 \%$. To stabilise cadmium concentrations in urine, adjustment to creatinine excretion is generally used. Creatinine excretion, however, varies by approximately $25 \%$ between individuals. ${ }^{15}$ Variations in urinary cadmium excretion, expressed as $\mu \mathrm{g} / \mathrm{g}$ creatinine, thus can be assumed to be caused partly by variation in creatinine excretion.

\section{Conclusions}

The concentrations of cadmium in blood and urine were found to be stable during a period when atmospheric levels of cadmium were low. The average coefficient of variation of cadmium was $17 \%$ in blood and $28 \%$ in urine (expressed as $\mu \mathrm{g} \mathrm{Cd} / \mathrm{g}$ creatinine). The latter variation is assumed to depend to a certain extent on variations in creatinine excretion.

Despite the low current level of atmospheric cadmium in the factory, workers who smoke may attain substantial exposure concentrations. The most likely explanation for this is that cadmium dust may contaminate cigarettes and pipe tobacco. Individual differences regarding personal hygiene appear to be of great importance. Cadmium dust can easily contaminate fingers and face, thereby giving rise to gastrointestinal exposure to cadmium as shown by Adamsson $e a^{3}$ and Roels et al. ${ }^{9}$

Supported by grant $76 / 227$ from the Swedish Workers' Protection Fund.

\section{References}

' National Swedish Board of Occupational Safety and Health. Cadmium. Stockholm: 1978. (In Swedish.)

${ }^{2}$ Adamsson E. Long-term sampling of airborne cadmium dust in an alkaline battery factory. Scand $J$ Work Environ Health 1979;5:178-87.

${ }^{3}$ Adamsson E, Piscator M, Nogawa K. Pulmonary and gastrointestinal exposure to cadmium oxide dust in a battery factory. Environ Health Perspect 1979;28:219-22.

4 Ulander A, Axelson O. Measurements of blood-cadmium levels. Lancet, 1974;i:682-3.

5 Elinder C-G, Kjellström T, Linnman L, and Pershagen G. Urinary excretion of cadmium and zinc among persons from Sweden. Environ Res 1978;15:473-84.

' Hare RS. Endogenous creatinine in serum and urine. Proc Soc Exp Biol Med 1950;74:148-51.

${ }^{7}$ Juda J, Budzinski, K. Fehler bei der Bestimmung der mittleren 
Staubkonzentration als Funktion der Anzahl der Einzelmessungen. Staub Reinhaltung der Luft 1961;24:283-7.

- Coenen W. Zur Frage des Vertrauensbereiches bei Mittelwerten der Staubkonzentration. Staub Reinhaltung der Luft 1966;26:216-21.

9 Roels H, Buchet J-P, Truc J, Croquet F, Lauwerys R. The possible role of direct ingestion and the overall absorption of cadmium or arsenic in workers exposed to $\mathrm{CdO}$ or $\mathrm{As}_{2} \mathrm{O}_{3}$ dust. American Journal of Industrial Medicine 1982;3:53-65.

${ }^{10} \mathrm{Kjellström} \mathrm{T.} \mathrm{Accumulation} \mathrm{and} \mathrm{renal} \mathrm{effects} \mathrm{of} \mathrm{cadmium} \mathrm{in} \mathrm{man.}$ Department of Environmental Hygiene, Karolinska Institute, Stockholm: 1977. (Doctoral thesis.)

" Lauwerys R, Roels H, Buchet J-P, Bernard A, Stanescu D.
Investigations on the lung and kidney function in workers exposed to cadmium. Environ Health Perspect 1979;28: $137-45$.

${ }^{12}$ Nordberg G, Kjellström T. Metabolic model for cadmium in man. Environ Health Perspect 1979;28:211-7.

${ }^{13}$ Friberg L, Piscator M, Nordberg G, Kjellström T. Cadmium in the environment. 2nd ed. Cleveland, Ohio, CRC Press, 1974.

14 Piscator M, Kjellström T, Lind B. Contamination of cigarettes and pipe tobacco by cadmium-oxide dust. Lancet 1976;ii:587.

is Koch C-D, Arnst E, Rommel K. Harnstoff, Kreatinin, Harnstoff- und KreatininClearance: Untersuchungen an 25 gesunden Probanden über ein Jahr. J Clin Chem Clin Biochem 1980;18:423-9. 